\title{
Sobre animales y desahucios
}

\section{María González Lacabex. ${ }^{1}$}

A pesar de los datos que apuntaban al sector de las mascotas como uno de los más resistentes a los efectos de la crisis (por la reticencia observada en los dueños a la hora de recortar en gastos relativos a sus animales), finalmente parece que la difícil coyuntura económica que atraviesa el país está afectando también a quienes no tienen - en este caso sin ningún género de duda - responsabilidad alguna sobre ella².

Asociaciones de protección animal y centros de acogida alertan sobre cómo la pérdida de empleo, las dificultades para hacer frente a las deudas, la necesidad de cambiar de vivienda... están llevando a propietarios de animales a tomar la decisión de deshacerse de sus mascotas ${ }^{3}$. Propietarios que, abrumados por los problemas económicos, acuden a estas asociaciones y centros con la intención de entregar a su animal, para que se

\footnotetext{
${ }^{1}$ Abogada. Máster en Derecho del Medio Ambiente. Especialista Universitaria en Desarrollo Sostenible y Agenda 21 Local. Tras cursar el Postgrado Animales, Derecho y Sociedad (UAB, 2011), ha dirigido su actividad profesional al ámbito del Derecho Animal, con su nuevo despacho ANIMALEX.

${ }^{2}$ Los medios de comunicación difundían recientemente el terrible dato de que unos 5.000 equinos son sacrificados cada mes en mataderos españoles, a lo que se añade el aumento del abandono de estos animales por su elevado coste de cuidado y mantenimiento. (El Correo, 10-07-2012: Una matanza de caballo) http://www.elcorreo.com/vizcaya/v/20120710/sociedad/matanza-caballo-20120710.html 3 Según el Estudio Fundación Affinity sobre el Abandono de Animales de Compañía, los casos de abandono por motivos económicos y de cambio de domicilio han aumentado hasta constituir casi un tercio del total (27\%). http://www.fundacion-affinity.org/sites/default/files/EstudioAbandono2010.pdf
} 
encarguen de él y puedan encontrarle un nuevo hogar. Una práctica que no es novedosa y que suele ser conocida como "abandono responsable" ${ }^{4}$.

Dejando a un lado lo contradictorio del término (personalmente encuentro gran dificultad a la hora de atribuir el calificativo responsable a la acción de abandono; en su lugar, me inclinaría por hablar de abandono "menos irresponsable", comparado con el acto de dejar a un animal solo y a su suerte), desde un punto de vista jurídico esta expresión suscita la siguiente pregunta: Para la ley y el Derecho ¿constituye realmente esta acción un acto de abandono? El dueño que acude a un centro de recogida a entregar a su animal, ¿lo está abandonando desde una estricta consideración jurídica? No es ésta una cuestión baladí. Por un lado, determinar si esta acción puede ser considerada jurídicamente como abandono es una cuestión relevante a efectos de sanción: En España, las 17 leyes autonómicas de protección animal vigentes en la actualidad establecen que el abandono está prohibido, calificándolo como infracción grave o muy grave y estableciendo las correspondientes sanciones ${ }^{5}$.

Por otro lado, aclarar si en estos supuestos estamos o no ante un abandono es importante a efectos de determinar la obligación del centro de recoger a los animales que le son entregados de esta manera, especialmente si se trata de centros públicos. En este sentido, todas las leyes de protección animal atribuyen a los ayuntamientos (o, en su caso, otras entidades locales), la competencia de la recogida de animales

\footnotetext{
${ }^{4}$ De acuerdo con el informe citado (supra n.3), 4 de cada 10 animales recogidos por los centros son llevados personalmente. La mitad de estos casos, quienes los llevan son quienes realizan el abandono.

${ }^{5}$ El art. 631.2 del Código Penal español castiga el abandono de animal doméstico únicamente cuando dicho abandono se realice en condiciones en que pueda peligrar su vida o su integridad (vid. en la Base de datos, bajo la voz "Abandono" http://www.derechoanimal.info/esp/basededatos/index). Con este matiz jurídico, la entrega del animal directamente al centro de recogida difícilmente tendría cabida en la actual redacción del tipo penal (también en relación con este tema, vid. T. Giménez-Candela, Sam, un perro anciano. Julio 2012 http://www.derechoanimal.info/esp/page/2133/sam-un-perro-anciano).
} 
abandonados. Pero ¿qué significa para estas leyes abandonar? ¿Qué es un animal abandonado? ¿Están obligados los ayuntamientos a hacerse cargo de los animales que son entregados directamente por sus propietarios?

La actual normativa sobre protección animal no ofrece una regulación ni clara, ni unívoca sobre el abandono. Algunas de estas leyes incorporan otros conceptos tales como animal errante, vagabundo o perdido, en algunos casos en equiparación al de animal abandonado, y en otros como categorías diferentes. Pero lo cierto es que un animal que vaga solo por la calle no debería ser considerado a priori como abandonado (puede haberse extraviado), ni siquiera si no porta la debida identificación (lo cual podrá constituir una infracción administrativa, pero no presume la voluntad del propietario de abandonarlo). En puridad, sólo debería considerarse abandonado el animal cuya pérdida no ha sido denunciada y que no ha sido recuperado después del plazo legal establecido.

De cualquier modo, para dar respuesta a esta cuestión habrá que estar, en cada caso, a lo que establezca la ley autonómica correspondiente (además de, si existe, la ordenanza municipal en materia de tenencia de animales). No obstante, sin perjuicio de las particularidades de la norma que en cada supuesto resulte aplicable, en general podemos decir que con el término animales abandonados las leyes de protección animal pretenden hacer referencia a aquellos animales que son encontrados solos, sin la compañía de persona que se responsabilice de ellos. Así, atendiendo al espíritu de estas leyes, no parece que el animal que es entregado directamente por su propietario pueda considerarse abandonado stricto sensu. De hecho, varias Comunidades Autónomas recogen expresamente en sus normativas la posibilidad de que los propietarios entreguen a sus animales cuando no se puedan hacer cargo de ellos, 
como alternativa legal al abandono, que sí está prohibido y sancionado ${ }^{6}$. De acuerdo con esto, jurídicamente la entrega del animal por parte de su dueño constituye más una cesión que un abandono. Una cesión que, por otro lado, no estarían obligados a admitir aquellos ayuntamientos donde la ley no recoja disposición expresa al respecto, si entendemos que su competencia se limita exclusivamente a la recogida de animales abandonados.

Al margen de consideraciones jurídicas, este tema pone sobre la mesa un debate que no era ajeno al día a día de protectoras y centros de acogida, pero que está ganando más actualidad si cabe con motivo de la crisis. Desde una perspectiva de protección animal, ¿̇resulta coherente aceptar animales entregados de esta manera? Más allá de los casos particulares, en el largo plazo ¿̇beneficia verdaderamente esta práctica a los animales? ¿Deben este tipo de entidades hacerse cargo también de aquellos cedidos voluntariamente por sus dueños?

En principio, existen argumentos a favor de una respuesta afirmativa: En primer lugar, la entrega por el propietario evita el riesgo que para la vida y la integridad física del animal supondría que lo dejara solo. Por otro lado, el contacto directo con el dueño proporciona a la entidad que recoge el animal la posibilidad de conocer sus antecedentes y recabar toda la información necesaria para favorecer su posterior adopción. Asimismo, esta práctica supone un ahorro en los costes asociados a la

\footnotetext{
${ }^{6}$ Así, por ejemplo, en Andalucía: “Los propietarios de animales de compañía podrán entregarlos, sin coste alguno, al servicio de acogimiento de animales abandonados de su municipio para que se proceda a su cesión a terceros y, en último extremo, a su sacrificio" (art.28.5 Ley 11/2003, de 14 de noviembre http://www.derechoanimal.info/bbdd/Documentos/255.pdf). O, en Aragón: “El propietario o poseedor de cualquier animal que no pueda continuar teniéndolo lo entregará en los centros de recogida establecidos por las Administraciones públicas" (art. 3.4 c Ley 11/2003, de 19 de marzo http://www.derechoanimal.info/bbdd/Documentos/270.pdf).
} 
captura y transporte de los animales, lo cual no resulta despreciable en un servicio con escasa disponibilidad presupuestaria y cada vez mayor demanda.

No obstante, al mismo tiempo resulta inevitable pensar que en un contexto de cría incontrolada, compra compulsiva, tenencia irresponsable, etc. puede ser cuando menos "poco pedagógico" lanzar a la ciudadanía el mensaje: "Hazte con un animal, que si luego no te va, te cansas o no puedes seguir manteniéndolo, lo devuelves y no pasa nada". Frente a esto, es posible que medidas como el abono de una tasa por la recogida del animal, la obligación de participar activamente en la búsqueda de adoptantes..., incluso tener que afrontar su sacrificio llegado el caso $^{7}$, puedan ser disuasorias, o al menos situar a quien piensa en entregar a su mascota en la verdadera magnitud del problema. O quizá lo realmente interesante sea actuar en clave preventiva, y asegurarnos de que quien decide incorporar un animal a su vida, conoce y asume el conjunto de compromisos - también los económicos - que ello va a implicar durante toda su existencia. Que comprende a su nuevo compañero como un ser con unas necesidades específicas y, sobre todo, con capacidad de sentir. Porque, al final, quien verdaderamente lo entienda así tendrá que hallarse en una situación francamente difícil, sin alternativa posible, para tomar la dolorosa decisión de separarse del animal con el que convive.

No parece descabellado que las leyes ofrezcan amparo a este tipo de supuestos extremos, atendiendo a las circunstancias de cada caso. Pero, reconociendo que

\footnotetext{
${ }^{7}$ Hay que recordar que, aunque muchas de las leyes de protección animal vigentes en España recogen expresamente que el sacrificio debe aplicarse siempre como último recurso, de forma que los animales sólo podrán ser sacrificados "en último término" (por ejemplo, en Galicia: art. 11 Ley 1/1993, de 13 de abril), "una vez transcurrido los plazos legales para su recuperación o adopción" (como en Baleares: art. 31 Ley 1/1992, de 8 de abril) o "cuando se haya hecho todo lo razonablemente exigible para encontrar un poseedor y no puedan ser atendidos por más tiempo en las instalaciones" (así, en Euskadi: art. 17 Ley 6/1993, de 29 de octubre), únicamente en Cataluña se encuentra prohibido con carácter general, "excepto por los motivos humanitarios y sanitarios que se establezcan por vía reglamentaria" (art. 11 Decreto Legislativo 2/2008, de 15 de abril).
} 


\section{dA derecho ANIMAL la web center de los animales con derecho}

podemos encontrarnos con situaciones personales y familiares límite (a las que sin duda habrá que tratar de apoyar y dar adecuada respuesta), algo falla en el hecho de que una legislación que se denomina a sí misma de protección animal admita con carácter general que es posible devolver a un animal cuando ya no encaja en tu vida. Reconocer que un animal "se puede devolver" ¿no es, en cierto modo, "cosificarlo"? No parece esto propio de unas leyes que, en principio, se fundamentan en los principios de respeto, defensa y protección de los animales, en la tenencia responsable y en la consideración de los animales como "seres sintientes 8 ".

Unas leyes que, en último término, deberían ir destinadas a salvaguardar los intereses de estos animales durante todos los estadios de su existencia, protegiéndolos frente a los posibles vaivenes de la vida de sus propietarios o poseedores. Leyes, en definitiva, dirigidas a evitar que también ellos, en tiempos de crisis, terminen desahuciados.

\footnotetext{
${ }^{8}$ Como reconoce expresamente el propio Tratado de Lisboa, que en su artículo 13 declara que los animales son "seres sintientes": "(...) the Union and the Member States shall, since animals are sentient beings, pay full regard to the welfare requirements of animals (...)".
} 